\title{
Causes of Child Mortality (1 to 4 Years of Age) From 1983 to 2012 in the Republic of Korea: National Vital Data
}

\author{
Seung Ah Choe, Sung-Il Cho \\ Department of Epidemiology, Graduate School of Public Health, Seoul National University, Seoul, Korea
}

Objectives: Child mortality remains a critical problem even in developed countries due to low fertility. To plan effective interventions, investigation into the trends and causes of child mortality is necessary. Therefore, we analyzed these trends and causes of child deaths over the last 30 years in Korea.

Methods: Causes of death data were obtained from a nationwide vital registration managed by the Korean Statistical Information Service. The mortality rate among all children aged between one and four years and the causes of deaths were reviewed. Data from 1983-2012 and 1993-2012 were analyzed separately because the proportion of unspecified causes of death during 1983-1992 varied substantially from that during 1993-2012.

Results: The child (1-4 years) mortality rates substantially decreased during the past three decades. The trend analysis revealed that all the five major causes of death (infectious, neoplastic, neurologic, congenital, and external origins) have decreased significantly. However, the sex ratio of child mortality (boys to girls) slightly increased during the last 30 years. External causes of death remain the most frequent origin of child mortality, and the proportion of mortality due to child assault has significantly increased (from 1.02 in 1983 to 1.38 in 2012).

Conclusions: In Korea, the major causes and rate of child mortality have changed and the sex ratio of child mortality has slightly increased since the early 1980s. Child mortality, especially due to preventable causes, requires public health intervention.

Key words: Child mortality, Cause of death, Sex ratio

\section{INTRODUCTION}

Improving the health of children is a great concern globally. As child mortality has become relatively lower than before, epidemiological changes have been observed in many developing and developed countries. Moreover, an epidemiological

Received: June 16, 2014 Accepted: November 5, 2014

Corresponding author: Sung-II Cho, MD, ScD

1 Gwanak-ro, Gwanak-gu, Seoul 151-742, Korea

Tel: +82-2-880-2717, Fax: +82-2-743-8240

E-mail:scho@snu.ac.kr

This is an Open Access article distributed under the terms of the Creative Commons Attribution Non-Commercial License (http://creativecommons.org/licenses/by$\mathrm{nc} / 3.0 /$ ) which permits unrestricted non-commercial use, distribution, and reproduction in any medium, provided the original work is properly cited. transition, in which infectious diseases recede and chronic diseases increase as the causes of death [1], has been suggested to have occurred in child populations worldwide [2]. According to previous reports, the proportion of congenital/perinatal causes of death tends to have increased among the total number of infant deaths, while the proportion of deaths due to external causes have increased for child mortality [2-5]. In addition, boys tend to show a higher mortality rate than girls during early childhood; therefore, the sex ratio of child mortality is expected to be higher than 1.0 [5]. However, historically, a higher mortality rate among girls aged between one to four years has been observed in many regions that strongly prefer to raise a son. This difference in mortality was suggested to be attributed to the fact that girls might receive less adequate care than that provided to boys in these regions $[5,6]$. 
The Republic of Korea (hereafter Korea) has experienced rapid social change and economic growth with substantial improvements to many general health indices including life expectancy. With the improved access to health care and development of intensive perinatal/neonatal care, infant mortality has also improved $[7,8]$. However, according to one previous report, the annual mortality in Korea from unintentional and intentional injuries among those aged between one to 14 years during 1991-1995 was the highest among the 26 high-income countries worldwide [9]. In addition, a prominently higher mortality among female Korean children was revealed from the mid-1960s to 1970s [6].

To date, few studies have investigated the trends of child mortality in this rapidly developed society. Herein, we aimed to identify whether epidemiological changes in child mortality have occurred during the past 30 years in Korea, which experienced dramatic socioeconomic change during that time.

\section{METHODS}

In 1987, approximately $90 \%$ of all deaths were certified [10], and by 2007 , almost $100 \%$ of all deaths were certified; however, infant death certification has not been as well maintained [11]. These death certificates record all of the conditions and probable causes of death for issue to the government $[11,12]$. Most of causes of death have been verified by a physician or other qualified personnel in Korea. Previously, the accuracy rates for the reported cause of death on the initial death certificate were found to be $43.9 \%$ [10] and $62.6 \%[13,14]$. The National Statistical Office has continued to make a strong effort to improve the accuracy of all death-related indices since 1982 [11]. Their efforts include reviewing medical records and crosschecking the exact cause of death in the corresponding hospitals where the death certificates were issued. The accuracy of the causes of death from data in the 2000s was found to be between $91.9 \%$ [14] and 95.1\% [15].

The child mortality rate was defined as the probability of dying between the ages of one to four years in reference to the definition by the World Health Organization and previous reports $[2,5,16]$. Annual data from 1983-2012 on deaths among children aged between one to four years were obtained from the Korea Statistical Information System [17]. From these data, the cause-specific probability of death per 100000 children was calculated by dividing the number of death from selected causes by the mid-year population of this age group [18]. To procure consistency and improve the possibility for international comparisons, the original data were merged with timeseries data from the previous years [19]. Cause of death in our death certificate data was classified using the International Classification of Diseases (ICD)-10. Among the major causes of death, the diagnostic codes for neurologic and respiratory diseases were reassigned to the infectious disease category following the protocol of two previous studies [20,21].

We analyzed changes to the mortality rate, the proportion of children in each cause of death, and the sex ratio in the target population. To allow for the comparison of our results with those of previous studies as well as account for the low accuracy infant death certificate from 1980 to 1999 in Korea [22], we chose to focus on only the mortality data among children aged between one to four years old. The sex ratio was calculated by dividing the mortality rate of boys by that of girls. To assess trends across the sex ratio and each cause of child mortality, the Mann-Kendall trend test was performed. The Mann-Kendall trend test is a nonparametric test for monotonic trends in a time series, based on the Kendall rank correlation between the value of interest and time [23]. This method was originally proposed by Mann [24] and has been a popular approach to testing environmental time trends [25]. It was also used by Davenport [26] in their study of the historical decline of tuberculosis mortality in the UK. All trend tests and plotting of changes in the mortality rate were done using $\mathrm{R}$ version 3.0.3 (R Foundation for Statistical Computing, Vienna, Austria). In the plots, loess smoothing lines were added.

\section{RESULTS}

To explore patterns in child mortality, the five leading causes of death during 1993-2012 were selected for our final analysis after excluding for any unspecified causes of death. Although respiratory and circulatory diseases were frequent causes of child death in 1983-1992, they were excluded in our analysis because they were ranked higher than the first through seventh causes of mortality in 1993-2012. We found a decreasing trend in annual child mortality rates (Figure 1). The child mortality rate had fallen from 202.3 to 20.2 in 1983 and 2012, respectively. Moreover, a modest increase was observed in sex ratio of child mortality, 1.03 in 1983 to 1.38 in 2012 . When classifying the cause of death using the ICD-10 system, this reduction in total child mortality was mainly attributed to the decrease in infectious (29\%), unclassified (29\%), and external 
causes (22\%) of child mortality (data not shown).

Among the major causes of death, external (ICD-10 code V01Y89), infectious (A00-B99, G00-G09, and J09-J18), neoplastic (CO0-D48), neurologic excluding infections (G20-G98), and congenital (Q00-Q99) origins have been the leading causes of death in this age group throughout the previous two decades (1993-2012). External causes of mortality had been the most frequent causes of death until recent years, but the proportion of these deaths has slightly decreased since the early 2000s. However, the portion of mortality due to neurologic and neoplastic causes has increased, now consisting of the second and third most frequent cause of death. Since the proportion of unspecified causes of death had been higher than 10\% before 1993, a trend test was done for the periods between 1983-2012 and 1993-2012, respectively. As shown in Table 1, the annual rates of child mortality due to all five major causes of death de-

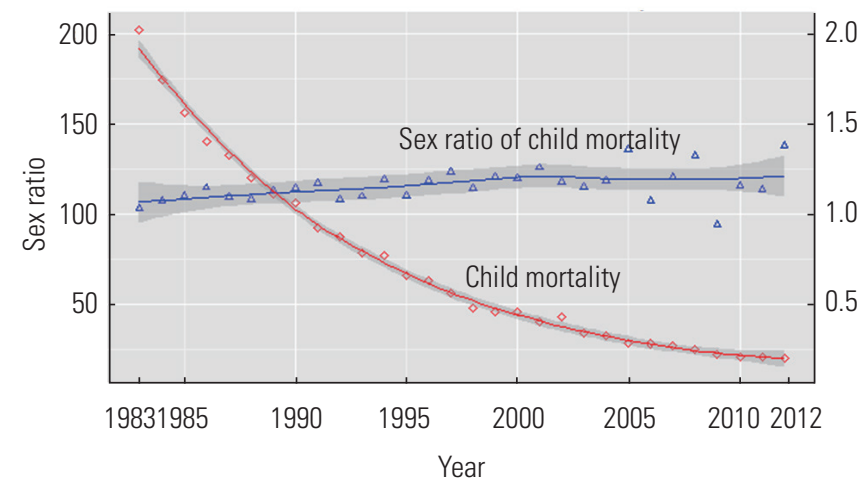

Figure 1. Annual rate and sex ratio (male to female) of child mortality (1-4 years of age) in Korea (1983-2012). Loess smoothing lines were added (with the shaded area representing two standard errors). creased significantly during the study period $(p<0.001$ for all data except neurologic causes during 1993-2012). Although the rate of unspecified causes of death was considerably high, death due to infectious disease was the most frequent cause of death among children aged one to four years in the early 1980 s. In addition, the least frequent causes of death were infectious and unspecified causes by 2012.

The ratio of total child mortality among boys to girls ranged from 0.94 to 1.38 and showed an increasing trend from 1983 to 2012 (Kendall $\tau=0.38, p=0.003$ ). However, this increased trend was not observed during 1993-2012. Sex differentials in the annual mortality rate of each cause were calculated to identify the origin of excess mortality among males. No linear trend across the changes of all major causes of mortality was found (Table 2).

Table 3 shows the differences across the external causes of child mortality. External cause mortality decreased from 38.9\% to $29.3 \%$ in 1993 and 2012, respectively (Kendall $\tau=-0.75$, $p<0.001$ ), and was accompanied by a significant decrease in the mortality rate during the same period (Kendall $\tau=-0.98$, $p<0.001)$. When the external cause of death data were divided into three major components, the majority of diagnoses were either other accidental injuries (V01-V99) or transport accidents (W00-X59). The mortality rate due to transport accidents and other accidental injuries showed a decreasing trend (Kendall $\tau=-0.76, p<0.001$ for transport accidents; Kendall $\tau=-0.94$, $p<0.001$ for other accidental injuries). From 1993 to 2012, the proportional death rate among all causes of mortality was significantly lower for both transport accidents and other accidental injuries than that among other causes were. On the contrary, the proportional mortality due to child assault (X85-Y09)

Table 1. The trends in the mortality rate across the five leading causes ${ }^{1}$ of child mortality (1983-2012)

\begin{tabular}{|c|c|c|c|c|c|c|c|c|c|}
\hline Cause of death ${ }^{2}$ & \multicolumn{3}{|c|}{ Mean $^{3}$} & \multicolumn{2}{|r|}{ Minimum } & \multicolumn{2}{|c|}{ Maximum } & \multicolumn{2}{|c|}{ Kendall tau ${ }^{4}$} \\
\hline $\begin{array}{l}\text { Infectious (A00-B99, G00, } \\
\text { G03, J09-18, J20-22) }\end{array}$ & 24.1 & 4.4 & 1.9 & 2008 & 1.1 & 1983 & 56.1 & $-0.89^{* * *}$ & $-0.74^{* * *}$ \\
\hline Neoplasm (CO0-D48) & 6.2 & 5.0 & 3.5 & 2010 & 2 & 1987 & 7.3 & $-0.73^{* * *}$ & $-0.76^{* * *}$ \\
\hline $\begin{array}{l}\text { Neurologic, excluding } \\
\text { infections (G20-G98) }\end{array}$ & 6.4 & 4.3 & 3.2 & 2009 & 2.4 & 1983 & 9.5 & $-0.73^{* * *}$ & $-0.55^{* *}$ \\
\hline Congenital (000-099) & 8.0 & 5.7 & 2.8 & 2008 & 2.3 & 1990 & 12.8 & $-0.63^{* * *}$ & $-0.81^{* * *}$ \\
\hline External (V01-Y89) & 46.8 & 27.4 & 9.4 & 2011 & 5.9 & 1988 & 50 & $-0.91 * * *$ & $-0.98^{* * *}$ \\
\hline
\end{tabular}

${ }^{1}$ Five leading causes of death from 1993 to 2012.

${ }^{2}$ Codes in parentheses are the International Classification of Disease 10th revision.

${ }^{3}$ Mean child mortality rate (per 100000 ) in each period.

${ }^{4}$ Mann-Kendall trend test was performed across all annual mortality rates in each period.

${ }^{* *} p<0.01,{ }^{* * *} p<0.001$. 
Table 2. The sex ratios (males to females) for total mortality and for each cause of child mortality in Korea (1983-2012)

\begin{tabular}{|c|c|c|c|c|c|c|c|c|c|}
\hline \multirow{2}{*}{ Cause of death ${ }^{1}$} & \multicolumn{3}{|c|}{ Mean $^{2}$} & \multicolumn{2}{|c|}{ Minimum } & \multicolumn{2}{|c|}{ Maximum } & \multicolumn{2}{|c|}{ Kendall tau ${ }^{3}$} \\
\hline & 1983-1992 & 1993-2002 & 2003-2012 & Year & Sex ratio & Year & Sex ratio & 1983-2012 & $1993-2012$ \\
\hline Total & 1.1 & 1.2 & 1.2 & 2009 & 0.9 & 2012 & 1.4 & $0.38^{* *}$ & 0.11 \\
\hline Infectious (A00-B99, G00-G09, J09-18, J20-22) & 0.9 & 1.0 & 1.1 & 2011 & 0.6 & 2003 & 1.4 & 0.21 & 0.06 \\
\hline Neoplasm (CO0-D48) & 1.1 & 1.2 & 1.2 & 2009 & 0.7 & 2005 & 1.9 & 0.17 & 0.07 \\
\hline Neurologic, except infection (G20-G98) & 1.2 & 1.2 & 1.2 & 2003 & 0.9 & 2012 & 1.6 & -0.04 & 0.04 \\
\hline Congenital (000-099) & 1.0 & 1.1 & 1.0 & 2005 & 0.6 & 2008 & 1.9 & -0.06 & -0.12 \\
\hline External (V01-Y89) & 1.4 & 1.3 & 1.4 & 2009 & 1.1 & 2012 & 1.9 & 0.02 & 0.24 \\
\hline Unspecified (R00-R99) & 1.0 & 1.1 & 1.1 & 2006 & 0.7 & 2012 & 1.7 & 0.19 & 0.15 \\
\hline Others & 1.0 & 1.0 & 1.1 & 2001 & 0.8 & 2011 & 1.9 & 0.09 & 0.07 \\
\hline
\end{tabular}

${ }^{1}$ Codes in parentheses are the International Classification of Disease 10th revision.

${ }^{2}$ Mean sex ratio of the child mortality rate.

${ }^{3}$ Mann-Kendall trend test was done for the annual sex ratio of mortality.

${ }^{* *} p<0.01$

Table 3. The trends of the three major external causes of child mortality from 1983 to 2012

\begin{tabular}{|c|c|c|c|c|c|c|c|c|c|c|}
\hline \multirow[t]{2}{*}{ External causes of death ${ }^{1}$} & \multicolumn{3}{|c|}{ Mean mortality rate ${ }^{2}$} & \multicolumn{3}{|c|}{ Proportional mortality rate ${ }^{3}(\%)$} & \multicolumn{2}{|c|}{$\begin{array}{c}\text { Kendall tau } \\
\text { for the mortality } \\
\text { rate }\end{array}$} & \multicolumn{2}{|c|}{$\begin{array}{l}\text { Kendall tau for } \\
\text { the proportional } \\
\text { mortality rate }(\%)\end{array}$} \\
\hline & 1983-1992 & 1993-2002 & 2003-2012 & 1983-1992 & 1993-2002 & $2003-2012$ & $1983-2012$ & 1993-2012 & 1983-2012 & 1993-2012 \\
\hline Total external causes (V01-Y89) & 46.8 & 27.4 & 9.4 & 37.4 & 48.5 & 35.5 & $-0.91^{* * *}$ & $-0.98 * * *$ & -0.06 & $-0.75^{* * *}$ \\
\hline Transport accidents (V01-V99) & 20.6 & 14.2 & 4.3 & 17.2 & 25.0 & 16.0 & $-0.76^{* * *}$ & $-0.95^{* * *}$ & -0.15 & $-0.81^{* * *}$ \\
\hline $\begin{array}{l}\text { Other accidental injuries } \\
\text { (W00-X49) }\end{array}$ & 17.8 & 8.6 & 2.9 & 13.3 & 15.5 & 10.7 & $-0.94^{* * *}$ & $-0.92^{* * *}$ & -0.22 & $-0.42^{*}$ \\
\hline
\end{tabular}

${ }^{1}$ Codes in parentheses are the International Classification of Disease 10th revision.

${ }^{2}$ Mean child mortality rate (per 100000 ) in each period.

${ }^{3}$ Proportional mortality rate (\%) among all of the causes of child mortality.

${ }^{4}$ Mann-Kendall trend test was performed across all annual mortality rate and proportion data.

${ }^{*} p<0.05,{ }^{* * *} p<0.001$.

has increased since 1993 (Kendall $\tau=0.66, p<0.001$ ). The trends across the annual mortality rates and the proportional mortality for deaths due to external causes are shown in Figure 2.

\section{DISCUSSION}

This study analyzed the trends related to causes of mortality among children aged between one to four years from 1983 to 2012. By excluding the mortality of infants, we hoped to avoid issues related to the lack of reliable infant death certificate data [11]. Since the most profound changes in the health and disease patterns during the epidemiologic transition occurs among children and young women [27], we were to identify the corresponding change in child mortality. During the past 30 years in Korea, there has been a dramatic decrease in overall child mortality as well as an increased proportion of non-infectious causes of death, similar to the trends in most developed countries. Ex- ternal causes of death were found to be the most common cause of child mortality; this finding is consistent with those in Japan [4], the US [28], and the UK [3]. Furthermore, the overall frequency of external causes of child death is decreasing in these countries. With the advance of medical/health care, the external causes of death are expected to become a relatively larger proportion of the overall mortality. However, approximately $40 \%$ of children aged between one and four years have died due to external causes, and this high proportion is not acceptable considering the fact that most cases of child injury are preventable [28].

External causes of death were the most frequent diagnosis of death throughout our study period; however, its proportion was found to steadily decrease compared to that of the neoplastic and neurologic causes of death. The increasing proportion of neoplastic and neurologic causes of death suggests the presence of an epidemiological transition from acute to chronic 

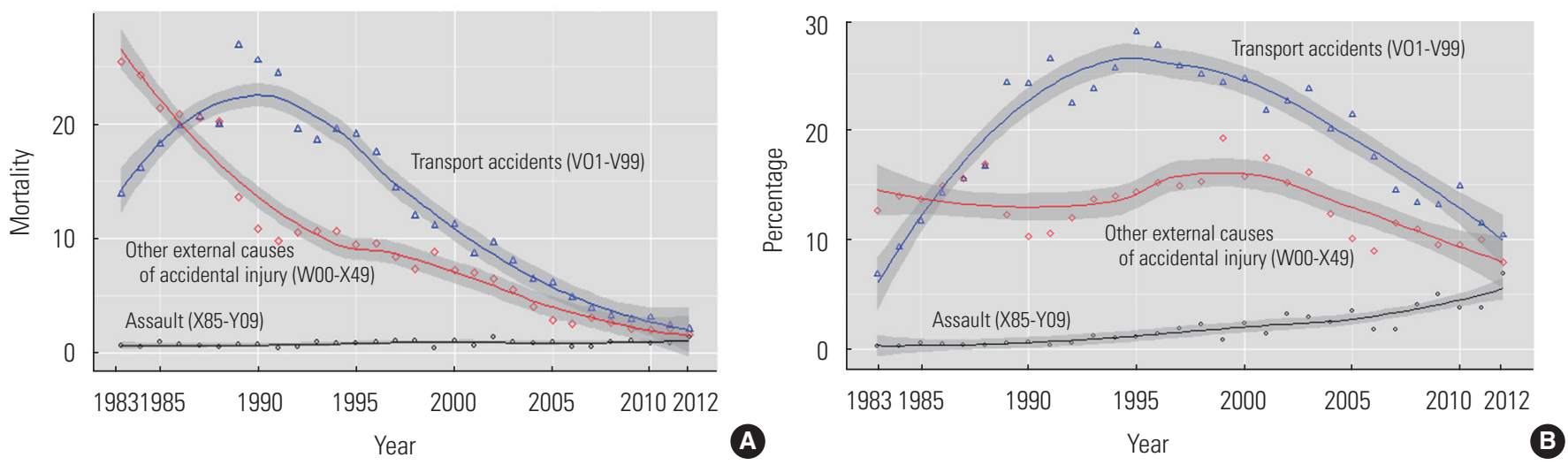

Figure 2. The trends of the three major external causes of child mortality from 1983 to 2012. (A) Changes in annual mortality rate among deaths from external causes. (B) Changes in proportional mortality (\%) among all cause of deaths. Loess smoothing lines were added (with the shaded area representing two standard errors).

conditions as the causes of death in this age group. In a report on child mortality (aged 1-4) in the US from 2005 to 2010, the leading causes of death were external, congenital, and heart disease [29]. Thus, the relatively high proportion of neoplastic and neurologic deaths in the present study requires further investigation.

Choe [6] reported an excess mortality among female children (aged 1-4 years). Their sex ratio of child mortality ranged from 0.81 to 0.94 from 1960 to 1974 [6]. Although their study used national survey data, the higher sex mortality ratio in our study might suggest that access to health care among female children has recently improved. Furthermore, if we consider the likelihood that female child mortality was under-reported in the early data collection periods [30], the sex ratios of child mortality in the 1960s and 1970s might have been smaller than the reported data [31,32]. Therefore, the increasing trend of this ratio since the 1980s was likely not affected by the sex-specific omission of child mortality events. According to the United Nations Population Division Report in 1998, numerous countries had higher mortality rates among girls aged between one and four years than that among boys [33]. This difference was suggested to be partially attributed to the differences in healthcare access and treatment among girls compared to boys [2,33]. In addition, female children tend to exhibit a survival advantage as mortality declines and infectious diseases become rare [30]. Globally, the sex ratio of child mortality has slightly increased from 1.02 in the 1980s to 1.11 in the 2000s, showing considerable variation across countries [2]. In the same period, the sex ratio of child mortality in developed countries was held constant at approximately 1.24 , suggesting that more deaths consistently occurred in boys than girls [2]. In several developing countries, the sex ra- tio of child mortality in this age group significantly increased, therefore indicating that female mortality had declined [34]. The mean sex ratio in Korea was similar to that of other developed countries across the three decades. However, when the annual sex ratio of total mortality was analyzed, there was a significant increase in the sex ratio during the 1983-2012 period. The lack of change to the sex ratio of total mortality during 1993-2012 might suggest that biologically determined sex differentials are influencing survival more than other factors are in Korean children aged between one and four years. If true, this trend would be similar to those in other developed countries [2].

The increasing proportional mortality due to assault is remarkable. The mortality rate due to child assault has been approaching that of other accidental injury. This increased proportional mortality of child assault might be partially due to the dramatically reduced child mortality due to all other causes. Although the overall child mortality rate due to assault in Korea was reported to be lower than that in other countries [35], the increasing trend of child mortality due to assault should be further investigated. In 1980s and early 1990s, the tendency of child maltreatment to be under-reported may have been under-reported and resulted in the relatively low incidence of assault-related mortality at the time. However, considering the fact that concerns regarding increased cases of child abuse and assault in the richest countries grows [35,36], the true number and proportion of child assault may have increased in a similar trend. Furthermore, the number of deaths from child abuse has increased during 2001-2012 according to a national report [37]. Monitoring systems such as a child fatality review team should be implemented to prevent child deaths from maltreatment or intentional injuries [38]. 
The major limitation in our study is the low reliability of the cause of death data from 1980 to the early 1990s with a high proportion of unspecified diagnoses. However, the changing patterns of each kind of mortality are consistent with those of previous studies. Furthermore, since Korea has developed highly accurate death statistics $[11,14]$, this study is still a valuable addition to the literature on child mortality epidemiology.

In summary, the changing patterns in child mortality in Korea indicate that a typical transition has occurred during the past three decades. These transitions include a receding number of infectious causes of mortality and a slight increase in the sex ratio of child mortality. Among all of the causes of child mortality in Korea, the increased portion of assault-related deaths requires more public attention and prompt public health intervention in the near future.

\section{CONFLICT OF INTEREST}

The authors have no conflicts of interest with the material presented in this paper.

\section{REFERENCES}

1. McKeown RE. The epidemiologic transition: changing patterns of mortality and population dynamics. Am J Lifestyle Med 2009; 3(1 Suppl):19S-26S.

2. United Nations, Population Division. Sex differentials in childhood mortality. New York: United Nations; 2011, p. 66.

3. Hardelid P, Davey J, Dattani N, Gilbert R; Working Group of the Research and Policy Directorate of the Royal College of Paediatrics and Child Health. Child deaths due to injury in the four UK countries: a time trends study from 1980 to 2010. PLoS One 2013:8(7):e68323.

4. Sekii H, Ohtsu T, Shirasawa T, Ochiai H, Shimizu T, Kokaze A. Childhood mortality due to unintentional injuries in Japan, 2000-2009. Int J Environ Res Public Health 2013;10(2):528-540.

5. Sawyer CC. Child mortality estimation: estimating sex differences in childhood mortality since the 1970s. PLoS Med 2012;9(8): e1001287.

6. Choe MK. Sex differentials in infant and child mortality in Korea. Soc Biol 1987;34(1-2):12-25.

7. Van den Heuvel M, Hopkins J, Biscaro A, Srikanthan C, Feller A, Bremberg $S$, et al. A comparative analysis of early child health and development services and outcomes in countries with different redistributive policies. BMC Public Health 2013;13:1049.
8. Chuang YC, Chuang KY, Chen YR, Shi BW, Yang TH. Welfare state regimes, infant mortality and life expectancy: integrating evidence from East Asia. J Epidemiol Community Health 2012; 66(7):e23.

9. United Nations Children's Fund, International Child Development Centre. A league table of child deaths by injury in rich nations. Florence: United Nations Children's Fund; 2001, p. 4.

10. Lee MC, Kim CH, Yoo TW, Huh BY, Park DK, Kim SY, et al. Errors in death certificates in Korea. J Korean Acad Fam Med 1992; 13(5):442-449 (Korean).

11. Kim SY. Study on complement of death statistics in Korea. Daejon: Statistical Research Institute; 2008, p. 1-4 (Korean).

12. Ministry of Government Administration and Home Affairs. Information about Korean civil services and policies 2013 [cited 2014 Aug 23]. Available from: http://www.korea.go.kr (Korean).

13. Chung EK, Shin HY, Shin JH, Nam HS, Ryu SY, Im JS, et al. Accuracy of the registered cause of death in a county and its related factors. Korean J Prev Med 2002;25(2):153-159 (Korean).

14. Won TY, Kang BS, Im TH, Choi HJ. The study of accuracy of death statistics. J Korean Soc Emerg Med 2007;18(3):256-262 (Korean).

15. Korea National Statistical Office. Evaluate and improve the accuracy of cause of death statistics. Seoul: Korea National Statistical Office; 2009, p.1-35.

16. United Nations Children's Fund; World Health Organization; World Bank; United Nations. Levels and trends of child mortality in 2006. New York: Inter-agency Group for Child Mortality Estimation; 2007, p. 9-21.

17. Korean Statistical Information Service. Deaths and death rates by cause (103 item), by sex, by age (five-year age) [cited 2014 Aug 25]. Available from: http://kosis.kr/eng/statisticsList/ statisticsList_01List.jsp?vwcd = MT_ETITLE\&parmTabld =M_0 1_01\#SubCont.

18. Department of Population and Migration. Cause of death 2012. Daejeon: Statistics Korea; 2012, p. 48 (Korean).

19. Korean Statistical Information Service. Survey outlines, deaths by cause 2012 [cited 2014 Sept 25]. Available from: http:// meta.narastat.kr/metasvc/index.do?orgld $=101 \&$ confmNo $=1$ 0154\#iem201222 (Korean).

20. Million Death Study Collaborators, Bassani DG, Kumar R, Awasthi S, Morris SK, Paul VK, et al. Causes of neonatal and child mortality in India: a nationally representative mortality survey. Lancet 2010;376(9755):1853-1860.

21. Black RE, Cousens S, Johnson HL, Lawn JE, Rudan I, Bassani DG, et al. Global, regional, and national causes of child mortality in 
2008: a systematic analysis. Lancet 2010;375(9730):1969-1987.

22. Han YJ, Choi JS, Lee SW, Seo K, Oh HC, Lee SW, et al. Study of level and characteristics of under 5 mortality. Seoul: Ministry of Health and Welfare; 2009, p. 19-85 (Korean).

23. Kendall MG. Rank correlation methods. 4th ed. London: Griffin; 1975, p. 5-47.

24. Mann HB. Nonparametric tests against trend. Econometrica 1945;13(3):245-259.

25. Hipel KW, McLeod Al. Time series modelling of water resources and environmental systems. Amsterdam: Elsevier; 1994, p. 883.

26. Davenport RJ. Year of birth effects in the historical decline of tuberculosis mortality: a reconsideration. PLoS One 2013; 8(12):e81797.

27. Omran AR. The epidemiologic transition: a theory of the epidemiology of population change. Milbank Mem Fund Q 1971; 49(4):509-538.

28. Johnston BD, Ebel BE. Child injury control: trends, themes, and controversies. Acad Pediatr 2013;13(6):499-507.

29. Centers for Disease Control and Prevention. 10 Leading causes of death by age group, United States: 2005-2010. Atlanta: Centers for Disease Control and Prevention; 2006-2011.

30. Hill K, Upchurch DM. gender differences in child health: evidence from the demographic and health surveys. Popul Dev
Rev 1995;21(1):127-151.

31. Hesketh T, Xing ZW. Abnormal sex ratios in human populations: causes and consequences. Proc Natl Acad Sci U S A 2006;103(36): 13271-13275.

32. Gu B, Roy K. Sex ratio at birth in China, with reference to other areas in East Asia: what we know. Asia Pac Popul J 1995;10(3): 17-42.

33. United Nations. Too young to die: genes or gender? New York: United Nations; 1998, p. 208-222.

34. World Health Organization. Women and health: today's evidence tomorrow's agenda. Geneva: World Health Organization; 2009, p. 6-11.

35. United Nations Children's Fund. A league table of child maltreatment deaths in rich nations [cited 2014 Nov 14]. Available from: http://www.unicef-irc.org/publications/353.

36. Jenny C, Isaac R. The relation between child death and child maltreatment. Arch Dis Child 2006;91(3):265-269.

37. National Child Protection Agency. National report on state of child abuse. Seoul: Ministry of Health and Welfare; 2012, p. 191-193 (Korean).

38. Rimsza ME, Schackner RA, Bowen KA, Marshall W. Can child deaths be prevented? The Arizona Child Fatality Review Program experience. Pediatrics 2002;110(1 Pt 1):e11. 